IJM

42,8

Received 11 September 2020

Revised 21 January 2021

7 May 2021

10 May 2021

Accepted 10 May 2021

\section{Wealth transfers and labour supply: impact of inheritances and gifts by gender in Europe}

\author{
Miguel Á. Malo \\ Department of Economics and Economic History, University of Salamanca, \\ Salamanca, Spain, and \\ Dario Sciulli \\ Department of Economic Studies, \\ Universita degli Studi Gabriele d'Annunzio Chieti e Pescara, Pescara, Italy
}

\begin{abstract}
Purpose - The authors analyse how the receipt of a wealth transfer (inheritance or gift) affects labour force participation in $14 \mathrm{EU}$ countries. They compare the effect of receiving an inheritance or a gift and investigate different behaviours at the gender level and educational level and for elderly individuals.

Design/methodology/approach - The authors use data from the Household Finance and Consumption Survey for 14 European countries and adopt an instrumental variable approach. They use information on the type of donor (family and nonfamily) to infer the degree of anticipation of a wealth transfer.

Findings - The authors find that unexpected wealth transfers have a negative impact on labour force participation, with a stronger impact for gifts than for inheritances. For gender, they find larger negative impacts for females than for males, which is in line with a weaker attachment to the labour market. Receiving an unexpected wealth transfer may also result in early retirement.

Originality/value - The paper offers a novel comparison of the effect of receiving an inheritance or a gift on labour force participation using a unique European dataset. The authors investigate whether males and females react differently to the receipt of a wealth transfer and the existence of different responses at the educational level and for elderly individuals.
\end{abstract}

Keywords Gender, Gift, Inheritance, Endogeneity, Labour supply

Paper type Research paper

\section{Introduction}

Whether inheritances have a negative impact on labour supply is a long-standing issue in labour economics. A simple economic explanation is that heirs experience a significant income effect, assuming that leisure is a normal good. This is usually known as Carnegie's conjecture. Accordingly, Holtz-Eakin et al. (1993) found that receiving a large inheritance significantly increased the likelihood of a single heir quitting the labour force. However, their results also suggested that those expecting a large inheritance decreased their labour force years before receiving the inheritance. Later literature developed richer results assessing the impacts of subjectively expecting an inheritance (Brown et al., 2010), windfall gains from lotteries (Imbens et al., 2001) and the impact of taxes on different types of wealth transfers (Poterba, 2001) on labour market outcomes. This literature shows that the negative impact on employment is much larger for unexpected inheritances, lottery winners tended to reduce

(C) Miguel Á. Malo and Dario Sciulli. Published by Emerald Publishing Limited. This article is published under the Creative Commons Attribution (CC BY 4.0) licence. Anyone may reproduce, distribute, translate and create derivative works of this article (for both commercial and non-commercial purposes), subject to full attribution to the original publication and authors. The full terms of this licence may be seen at http://creativecommons.org/licences/by/4.0/legalcode

Funding: Miguel Á. Malo acknowledges funding from the research project SA049G19 for research groups in the region of 'Castilla y Leon'.
International Journal of Manpowe Vol. 42 No. 8,2021 pp. $1450-1478$ Emerald Publishing Limited 0143-7720

DOI 10.1108/IJM-09-2020-0425

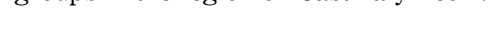


their labour earnings but not so clearly when jobs were psychologically or financially rewarding, and rich individuals consider gifts and inheritances only as partial but not total substitutes when facing taxes. Therefore, the relationship between wealth shocks and employment is richer and more complex than usually assumed by Carnegie's conjecture.

This article studies how receiving a wealth transfer affects labour force participation in Europe. We add to the previous literature comparing the impacts of different types of wealth shocks (inheritances and gifts) by providing separate estimates by gender and using homogeneous data from 14 European countries.

Inheritances and gifts share some common characteristics. For example, there is a higher probability that they come from family members than from other relatives or strangers. In fact, simple reasoning would suggest that gifts may only be an anticipated share of a future inheritance. However, there is previous literature suggesting that inheritances and gifts are not perfect substitutes, even for richer individuals who are aware of the differences in tax regimes for both types of wealth transfers (Poterba, 2001; Joulfaian and McGarry, 2005; McGarry, 2013). Therefore, it is of interest to test whether the impacts of inheritances and gifts on labour supply are the same.

There is little previous literature that provides estimations separated by gender. The few results by gender show significant negative impacts of inheritances for women but nonsignificant results for men (Doorley and Pestel, 2020; Bø et al., 2019). These results are in line with the well-known empirical pattern of a more elastic labour supply for females (e.g. Blau and Kahn, 2007).

Existing empirical analyses have more frequently investigated the American situation while European countries have been less investigated (e.g. Taylor, 2001 for the UK, Elinder et al., 2012 for Sweden, Doorley and Pestel 2020 for Germany). Recently, Sila and Sousa (2014) investigated the situation of European workers in EU-15 countries using data from the 19942001 ECHP. Our dataset is from the Household Finance and Consumption Survey, which was launched by the European Central Bank; the analysis is based on the 2014 wave. The survey contains detailed information on different financial features of European households, which is very suitable for our research.

Regarding the econometric specification, our empirical approach is based on estimations of the determinants of labour force participation - defined as a dummy variable - and we introduce variables for the two types of wealth shocks, namely, inheritances and gifts, in separate equations. In addition, we separate the estimation by the type of donor (family and nonfamily donor), which is information we use to infer the degree of anticipation of wealth transfers.

Both the probability of receiving an inheritance and the amount of the wealth transfer are likely to be guided by unobservable variables also affecting the probability of being in the labour force. Unobservable characteristics of the donor, including taste for leisure and risk aversion, may affect both the original family's wealth and the heir's cognitive and noncognitive skills with consequences for the richness of the inheritances and later labour market outcomes of the heir. For similar reasons, an omitted variable problem may arise when estimating the impact of having received a gift or when considering the effect of receiving different gift amounts. We address these problems by adopting an instrumental variable (IV) estimating labour force participation using a two-stage least squares (2SLS) estimator.

First, we instrument the inheritance variable using the (number of) deaths by transport accidents-to-population ratio because we assume that it is highly correlated with the probability of receiving an inheritance and that the inheritance is directly correlated with the death of a person. In addition, we consider the instrument is uncorrelated with the error term in the main regression, conditional on the other covariates, a hypothesis we test running underidentification and weak identification tests.

Second, we instrument the gift variable with information on wealth transfer tax changes. The instrument is a dummy variable indicating whether an individual has received a gift 
IJM

42,8

under a new tax regime. Therefore, we assume that a change in the tax regime affects both the probability of receiving a gift and the amount received, but it is uncorrelated with the response variable. All the results of the underidentification and weak identification tests confirm that this econometric specification is trustworthy and that the estimated effects are reliable.

\section{2}

\section{Literature}

The starting point for the impact of inheritances on the labour supply is Carnegie's conjecture, which is named after philanthropist Andrew Carnegie, who proposed that large inheritances have a negative impact on the labour force participation of heirs (Holtz-Eakin et al., 1993). The classical paper by Holtz-Eakin et al. (1993) found that, generally, Carnegie was right. For example, single heirs receiving $\$ 150,000$ were four times more likely to quit the labour force than those receiving $\$ 25,000$. They also found that families receiving a large inheritance decreased the growth of their labour earnings compared to those receiving smaller inheritances, suggesting a decrease in working hours even when remaining at work. However, being in the labour force before receiving an inheritance was also crucial for remaining in or leaving the labour force. Therefore, those expecting a large inheritance likely decreased their labour force years before receiving the inheritance.

The literature has considered whether the wealth shock is expected by the beneficiary. If an individual expects she will receive an inheritance from her parents, she will adapt her entire intertemporal consumption and working hour choices. Therefore, we would find a significant difference in labour force participation or working hours after the reception of an unexpected inheritance but not in the case of an expected inheritance. Brown et al. (2010) distinguished both types of inheritances, and they find that both affect the retirement decision, but the negative impact of an unexpected inheritance is larger. In general, it is difficult to find a variable to clarify this distinction. Some authors have focused on lottery winners to estimate the impact of a large, unexpected wealth shock on the labour supply. Imbens et al. (2001) found that lottery winners reduce their labour earnings. This effect is larger for older winners, which agrees with a standard life cycle labour supply model. However, Kaplan (1987) also reported descriptive evidence that individuals in more rewarding jobs - either psychologically or financially - continued working regardless of the amount they won while people in semiskilled and unskilled jobs exhibited a higher likelihood of quitting the labour force. Cesarini et al. (2017) and Picchio et al. (2018) found that winning a lottery prize produced a significant but modest impact on the labour supply in Sweden and the Netherlands, respectively.

However, previous literature may assume that there are few differences between gifts (inter vivos transfers) and inheritances, apart from their usually different sizes. Poterba (2001) remarks that large gifts and bequests can serve as substitutes for richer individuals. They can transfer wealth either by making gifts while they are alive (inter vivos gifts) or by leaving bequests. Furthermore, Poterba (2001) analysed the role of the tax system for the very rich to determine how, that is, through gifts or inheritances, (and when, i.e. before or after death) transfer income to their heirs. His analysis showed that the wealthiest anticipating bequests as present gifts are not taking full advantage of the tax system. Joulfaian and McGarry (2005) and McGarry (2013) collected evidence that gifts from wealthy parents are common, but their results are in line with Poterba (2001). Joulfaian and Wilhelm (1994) also showed that gifts are highly elastic with respect to tax changes, especially in the short run. Therefore, all this evidence suggests that individuals do not ignore taxes on gifts, but they do not consider gifts and inheritances perfect substitutes. Our interpretation of these empirical results on gifts is that individuals probably consider gifts and inheritances to be qualitatively different. Regarding the beneficiaries, there is also a key difference; while an inheritance is a one-shot 
transfer (per donor), there may be multiple gifts over time. However, a gift may be very similar to an in-kind transfer, as the donor may expect that the beneficiary will spend the transfer in a very specific way, which is not the case with an inheritance. In addition, from a macroeconomic perspective, Barro (1974) remarked on the role of inter vivos transfers to compensate for expected changes in the time tax schedule. Therefore, it is also crucial to distinguish expected and unexpected gifts to test their impact on labour force participation. In summary, all these differences between gifts and inheritances may lead to different impacts on the labour supply.

Finally, there are few previous studies that have provided estimations separated by gender. The response of the labour supply to the receipt of a wealth transfer may differ by gender following the empirical pattern of a greater responsiveness of the labour supply for women than for men (e.g. Blau and Kahn 2007). Because of the weaker link of many women with the labour market-related to the unequal distribution of domestic work and family care by gender, wealth transfers may have a stronger effect for them than for males. Doorley and Pestel (2020) estimated a decrease of 5 percentage points in the probability of working fulltime for women. The results for men are always not significant for employment postinheritance. Bø et al. (2019) also found a negative effect on post-inheritance employment for women and a nonsignificant effect for men.

However, interpreting the Carnegie effect being mainly driven by women must be careful as the larger impact for women may be driven by a three-options choice - work, caregiving, leisure - instead of a two-options choice - work and leisure - as in the basic neoclassical model. If a wealth shock decreases the labour supply and increases caregiving time, we do not have "lazy heirs" as in the Carnegie conjecture, but a sort of "family care effect" mostly resting on women because of the traditional division of labour in families. As Cox (2014) remarked, the impact of inheritances on caregiving is a pending topic in the literature on wealth shocks, which has probably been relegated because of the lack of suitable datasets. Nevertheless, the above results warn about relegating the "gender" variable just to a dummy in estimations.

\section{Data}

\subsection{The HFCS database}

The analysis is based on data from the Household Finance and Consumption Survey (HFCS), a survey conducted by the Household Finance and Consumption Network $(\mathrm{HFCN})$ and launched by the European Central Bank, the national central banks of the Euro system and several national statistical institutes. The HFCS provides information on more than 62,000 households in two different cross-sectional waves (2010 and 2014) across 18-euro area countries plus Hungary and Poland and constitutes a representative micro dataset at the euro area and member state level.

It provides data on labour market outcomes, including employment status, and several individual, household, and job-related characteristics. Importantly, the HFCS provides information on wealth transfers, which allows us to investigate their impact on the labour supply. Compared to other European datasets (e.g. the European Household Community Panel or the Survey of Incomes and Living Conditions), the use of the HFCS has several advantages. First, it allows us to differentiate the type of wealth transfer received (i.e. an inheritance or a gift). Second, the HFCS allows distinguishing the type of donor (family, parents and grandparent, non-family, other relatives and other individuals). Third, it reports the exact amount of the wealth transfer, so the information is accurate, and it can be converted into purchasing power parity (PPP) [1] terms, which allow for a more precise comparison across countries. Finally, it provides information on both past and recent wealth transfers, including the details of the year in which the wealth transfer occurred.

There are two shortcomings for our research related to the information provided by the HFCS. The first shortcoming is related to the dependent variable. As the HFCS is a cross-

\section{Wealth transfers and labour supply}

1453 
IJM

42,8

1454

sectional survey, we cannot estimate the impact of receiving an inheritance or a gift on the change in the employment statuses of the beneficiaries of these wealth transfers. Therefore, we analyse the impact of a past wealth transfer on current employment status. This may have some consequences on the results. For example, as males have a higher participation rate, the effects of past wealth transfers may be lower and/or hardly significant. To limit this problem, we control for the share of potential experience spent working as a proxy of previous statuses.

The second shortcoming is not explicitly distinguishing between expected and unexpected wealth transfers, which is relevant when identifying the impact of receiving a wealth transfer on the labour supply. However, address this drawback by exploiting information on the type of donor. We assume that receiving a wealth transfer from a family member (parents or grandparents) is significantly more likely to be anticipated by heirs than receiving a wealth transfer from other relatives or nonrelative donors, allowing us to infer the degree of anticipation of the wealth transfer.

Because the 2010 wave provides less complete information, we rely on the 2014 crosssectional wave. However, we exclude six countries from the analysis because of missing questions in the wealth transfer section (Finland, Italy and Spain) and many missing values in wealth transfer information (Cyprus, Greece and Malta); thus, 12 euro-area countries plus Hungary and Poland remain.

Our study indeed uses 2014 cross-sectional data to analyse the impact on labour force participation in this year after having received a wealth transfer in the previous 2008-2013 period. This wide timespan allows us to account for both short- and medium-term effects and is in line with some related studies (e.g. Imbens et al., 2001; Bø et al., 2019).

We focus on heads of household and their partners, both aged between 25 and 59 years old. The choice of this age range is helpful to avoid problems connected to educational and standard retirement decisions. In addition, we exclude both self-employed individuals (almost 6000 observations) and individuals who never entered the labour market (approximately 1,300 observations). The former, in fact, react quite differently than other workers to the receipt of a wealth transfer [2], while the latter are detached from the labour market. This selection leaves us with approximately 47,000 individuals, $29 \%$ of whom declared having received (at least) a wealth transfer.

\subsection{Descriptive statistics}

Descriptive statistics are reported in Table 1. For the 2008-2013 timespan, 7.5\% of the sampled individuals received (at least) an inheritance, and $5.2 \%$ received (at least) a gift. The related inheritance amount averaged across heirs is approximately 90,000 euros if expressed in purchasing power parity (PPP), while the average amount of gifts is approximately 94000 euros in PPP. Finally, the ratio of the average amount to the income of other household members in 2014 [3] is approximately 6.5 for inheritances and 7 for gifts. More detailed information about the distribution of the inheritances and gifts received in the 2008-2013 period is reported in the Appendix (Table A1).

We control for other sources of variability in the labour force participation equation. We account for gender, age (defined according to the four ranges of 25-34, 35-44, 45-54, and 5559), educational level (defined according to three different levels: low - up to primary education; medium - up to upper secondary education; and high - tertiary education), the presence of a working spouse, marital status and the number of children aged up to 6 years. We also include a dummy variable for foreign-born individuals, an indicator for previous employment history (i.e. the ratio of work experience and potential work experience), the unemployment rate in 2013 (defined according to country, gender and age groups), and country dummy variables that account for country-specific variability. Finally, we consider two instrumental variables, i.e. the (number of) deaths by transport accidents-to-population 


\begin{tabular}{lccccccccc}
\hline & & \multicolumn{3}{c}{ Inheritance } & \multicolumn{2}{c}{ Gift } & & Wealth \\
& Mean & Std err. & Mean & Std err. & Mean & Std err. & transfers and \\
labour supply
\end{tabular}

ratio (Eurostat, 2014) to instrument inheritance and a dummy variable indicating changes in gift taxes in the 2008-2013 period that we use to instrument gifts.

\section{Econometric specification}

Our analysis aims to assess the impact of having received a wealth transfer (i.e. an inheritance or a gift) in the 2008-2013 period on the probability of being in the labour force in 2014 for individuals aged 25-59 and living in fourteen European countries.

The benchmark model is based on the following regression equation:

$$
L F P_{i}=\alpha+X_{i} \beta+\gamma^{*} W T_{i}+\mu_{i} \text { where } W T=\text { inheritance, gift }
$$

$L F P_{i}$ is the labour force participation outcome in 2014. The variable is assigned a value of 1 if the individual participates in the labour market and 0 otherwise. Vector $X_{i}$ includes individual, familiar, and job-related characteristics and country dummy variables that we introduce to account for country-based heterogeneities; $\mu_{i}$ is a normally distributed error term. $\alpha$ and $\beta$ are unknown parameters to be estimated, and $\gamma$ is the parameter of interest measuring the impact of having received a wealth transfer on the outcome variable. Finally, WT is a wealth transfer (inheritance or gift) indicator for which we assume three alternative definitions: 
IJM

42,8

\section{6}

(1) First, $W T$ is a binary variable taking a value of one whether individual $i$ has received a wealth transfer in the reference period and zero otherwise.

(2) Second, $W T$ is a continuous indicator [4] measuring the amount of wealth transfer received in the reference period.

(3) Third, WT is a continuous indicator measuring the ratio between the amount of the wealth transfer received in the reference period and the income of other household members in 2014.

In principle, if equation (1) is assumed to have a linear functional form, we could estimate the parameters of interest $(\gamma)$ using the ordinary least squares (OLS). However, since the analysis is based on a cross-sectional dataset, we are unable to account for the potential omitted variables problem. In fact, both the probability of receiving an inheritance and the inheritance amount are likely to be guided by unobservable variables that also affect the probability of being in the labour force. Unobservable characteristics of the decedent, including taste for leisure and risk aversion, may affect both the original family's wealth and the heir's cognitive and noncognitive skills, with consequences for the richness of the inheritances and later labour market outcomes of the heir.

For similar reasons, an omitted variables problem may arise when estimating the impact of having received a gift or when considering the effect of receiving gifts with different amounts. In addition, when focusing on gifts, we possibly must address the reverse causality problem. For example, if an individual is unemployed or out of the labour force, ceteris paribus, it is more likely he/she receives a gift with the aim of starting a business, funding training, or making ends meet. This problem, however, is mitigated because of the absence of simultaneity between the current labour force participation and the timing of the gift receipt in our analysis and the exclusion of self-employed individuals from the analysis sample.

When an explanatory variable is endogenous, however, the zero conditional mean assumption is violated, and OLS estimates are inconsistent. We address the potential endogeneity of wealth transfer by adopting an instrumental variable (IV) approach to estimate labour force equations and by using a two-stage least squares (2SLS) estimator. The IV-2SLS procedure requires the instrument has to be highly correlated with the endogenous variable (relevance) and uncorrelated with the error term in the main regression, conditional on the other covariates (exogeneity).

When instrumenting the inheritance variable, we use the number of deaths by transport accidents-to-population at the country level (Eurostat, 2014). We increase the instrument's dimensionality by setting it at the year in which the inheritance was received; thus, it is defined along two dimensions: country and time.

We consider deaths by transport accidents to be highly correlated with the probability of receiving an inheritance and that inheritance is directly correlated with the death of a parent, other relatives and/or friends. The importance of the instrument is assessed using both an underidentification test and a weak identification test, and the related results are displayed in Table A2. A possible argument that possibly undermines the credibility of the exogeneity assumption is that the economic conditions of a country may be jointly correlated with both labour force participation and deaths by transport accidents. We account for this underlying mechanism by controlling for the 2013 unemployment rate (defined at country, gender and age levels) and including country-specific dummy variables. Additionally, with the aim of considering other aspects of economic conditions, we run an alternative specification that includes the GDP growth rate instead of the unemployment rate and country dummy variables. Once the country-level economic aspects are considered, we are confident that our IV identification strategy is robust. 
When instrumenting the gift variable, we exploit information on changes in wealth transfer taxes. In the last two decades, many European countries have revised or even abolished gift (and inheritance) taxes (European Commission, 2015), which provides country variability in the tax reform variable. The instrument, therefore, consists of a dummy variable indicating whether an individual has received a gift under a new tax regime. With the aim of increasing the dimensionality of our instrument, we set the indicator according to the year in which the gift has been received; then, it is defined along two dimensions, namely, country and time.

We consider that a change in the tax regime affects both the probability of receiving a gift and the amount received but is uncorrelated with the response variable, conditional on the other covariates. A reduction in gift taxes, for example, making gifts more affordable, may establish a substitution among different types of wealth transfer and then increase the probability an individual receives a gift. The importance of the instrument can be inferred by examining the statistics reported in Table A2.

Although the gift taxes per se are likely to be exogenous, we cannot exclude that gift tax changes occur in approximately the same period as other tax changes, including labour/ nonlabour income taxes, thus determining an underlying link with the error term via the tax policy orientation. For example, a less-tax-oriented policy maker is likely to reduce both taxes while a government favourable to greater public budgets is likely to increase both. However, while the implementation of coordinated tax policies is generally possible, it does not seem to be the case for the countries we analyse in the investigated period [5]. Despite this quite reassuring pattern, to understand whether and how contemporary variations in labour and wealth transfer taxes may affect our results, we run supplementary regressions in which we include alternative tax wedge indicators (in place of country dummy variables). We considered the tax wedge level in 2013, the average tax wedge level in the 2008-2013 period and the variation in the tax wedge in the 2008-2013 period.

To increase the robustness of our estimates, we account for sampling weights and use a Huber-White Sandwich estimator for the variance to obtain heteroscedasticity-consistent standard errors. Additionally, by clustering observations at the household level, we provide estimates that are robust to arbitrary intrahousehold correlation as it is assumed that observations are independent across households but not necessarily independent within households.

Finally, we provide a measure of the possible bias in instrumental variables' standard errors because of clustering at the country level. Following Angrist and Pischke (2009), we calculate the Moulton factor, which returns a measure of the bias in standard errors if the intraclass correlation is ignored. A Moulton factor equal to one indicates that there is no deviation in the estimation of standard errors related to clustering. Thus, our estimates are quite reassuring as the calculated Moulton factors range between 1.002 and 1.012 for the instrument of inheritance and between 1.014 and 1.059 for the instrument of gifts, suggesting that the bias of the standard errors is negligible (Table A6).

\section{Estimation results}

\subsection{Entire sample analysis}

We estimate the impact of having received a wealth transfer (inheritance or gift) in the 20082013 period on the probability of being in the labour force in 2014. Wealth transfers are considered by using three alternative indicators: (1) a binary indicator representing whether a wealth transfer was received, (2) a continuous indicator measuring the amount of the wealth transfer received (amount indicator), (3) a continuous indicator measuring the ratio between value of the amount of the wealth transfer received to the income of other household members (ratio indicator) [6]. Because the distribution of continuous-type indicators is highly unequal, 
IJM

42,8

1458

we convert them using the inverse hyperbolic sine (IHS) transformation with the aim of reducing the influence of outliers. To facilitate the interpretation of the related estimates, we report the value of the related elasticities $(\varepsilon)$ calculated at the means of the dependent and explanatory variables of interest next to the statistically significant estimated coefficients of the IHS transformed variables (see Bellemare and Wichman, 2020).

As wealth transfers are potentially endogenous in the estimated equations, we adopted an IV-2SLS strategy to estimate the parameters of interest. We test the goodness of the instruments by running both an underidentification test and a weak identification test. In the Appendix (Table A2), we show the Kleibergen-Paap $r k$ LM statistics and Kleibergen-Paap $r k$ Wald F statistics [7], which refer to the estimation results based on the entire sample. The underidentification tests reject the null hypothesis that the equations are underidentified, indicating that the excluded instruments are correlated with the endogenous regressors. The weak identification tests confirm the goodness of the adopted instruments. By comparing the Kleibergen-Paap $r k$ Wald F statistics with the Stock and Yogo (2005) critical values, the null hypothesis that the maximum relative bias due to weak instruments is greater than $10 \%$ is rejected (15\% in the case of the ratio indicator of gifts for nonfamily donors).

Table 2 reports estimates by comparing inheritances and gifts and distinguishing by the type of donor [8]. Starting with wealth transfers from family donors, we note that the impact of receiving an inheritance on the probability of being in the labour force is approximately zero and not statistically significant, regardless of the indicator we consider. This finding is consistent with the predictions of the lifetime labour supply model for which an anticipated inheritance does not affect the labour supply at the time of receipt. The impact of receiving a gift is negative, but the estimated coefficient is not statistically significant.

When assessing wealth transfers received from nonfamily donors, the impact is negative, greater in magnitude and statistically significant when focusing on inheritances. Having received an inheritance decreases the probability of being in the labour force by 6.38 p.p. ( $p$-value 0.021). The estimated coefficient of the amount indicator is -0.0181 ( $p$-value 0.024 , $\varepsilon=-0.02$ ) while the estimated coefficient of the ratio indicator is -0.0407 ( $p$-value 0.026 , $\varepsilon=-0.019)$. When focusing on gifts, our findings suggest that having received a gift from a nonfamily donor decreases the probability of being in the labour force by 7.29 p.p. The estimated coefficient, however, is not statistically significant, with the related $p$-value equal to 0.231 [9]. The estimated coefficients associated with the amount and the ratio indicators are -0.0204 ( $\phi$-value 0.236 ) and -0.0628 ( $\phi$-value 0.236$)$, respectively.

These results are confirmed once the GDP growth rate is controlled for in place of the 2013 unemployment rate and country dummy variables (Table A3). For example, the impact of receiving an inheritance from a nonfamily donor decreases the probability of being in the labour force by $6.61 \%$ ( $(p$-value 0.018$)$. In addition, the estimated coefficients of the impact of receiving a gift (and the amount) agree with those emerging from the benchmark analysis once tax wedge indicators are used (Table A4).

In summation, our estimates reveal that receiving a wealth transfer essentially reduces the probability of being in the labour force. The negative impact, however, differs based on the type of donor, being greater and statistically significant when the wealth transfers (particularly inheritances) are from nonfamily donors but smaller and statistically not significant when they are from family donors. This finding matches the evidence from Bø et al. (2019) who find that the impact of receiving a bequest in Norway is larger for indirect heirs than for direct heirs. Our findings are consistent with the prediction of the lifetime labour supply model for which the impact of receiving a wealth transfer depends on the degree of anticipation of the wealth transfer itself. The assumption that family and nonfamily donors are associated with different degrees of expectations also agrees with the arguments raised in Elinder et al. (2012) regarding the importance of the institutional context. Being that the succession rules in most European countries prohibit parents from completely disinheriting their children, beneficiaries are likely 


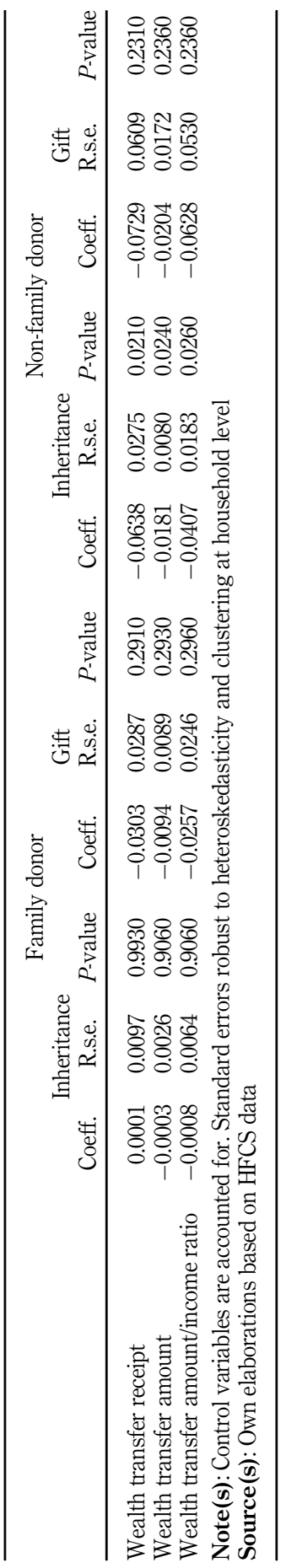

Wealth transfers and labour supply

1459

Table 2 .

The impact of wealth transfers on labour force participation: whole sample 
IJM

42,8

to perfectly anticipate the receipt of the wealth transfer from a family donor. However, nonfamily donors would be not (less) subjected to testamentary restriction rules, and then the related wealth transfers are more likely to be unanticipated.

We also stress that the impact associated with the receipt of a gift is greater in magnitude (even if not statistically significant) than the impact associated with the receipt of an inheritance, especially in the case of nonfamily donors. A possible interpretation is that the receipt of a gift from a nonfamily donor signals to the beneficiary the existence of a pool of money from which he/she may expect to receive further wealth transfers in the future. This is not the case for inheritances since the entire pool of money runs out with the bequest due to the donor's death. According to this view, the difference between a gift and an inheritance is that the former would incorporate an additional impact because of expected wealth transfers in the future. This explanation holds whether the future wealth transfer is received or not since just the expectation is relevant. It is obvious that the mentioned additional impact may vary across individuals (e.g. depending on their expectations), and this would be compatible with the greater variability of the estimated coefficients associated with gifts.

We test the robustness of our findings to the inclusion of self-employed individuals in the analysis (Table A7). Interestingly, in the case of nonfamily donors, the estimated coefficients are slightly smaller than those obtained from the original sample. This suggests that the effect related to self-employment slightly countervails the negative impact we find in our main analysis, which indicates that receiving an inheritance is positively correlated with staying or becoming self-employed (e.g. Holtz-Eakin et al., 1994; Taylor, 2001; Hurst and Lusardi, 2004).

\subsection{Analysis by gender}

Tables 3 and 4 report the analysis by gender. We find that the impact on males is smaller and statistically not significant, while the impact on females is negative (see Bø et al., 2019; Doorley and Pestel, 2020), greater in magnitude and statistically significant in the case of inheritances from nonfamily donors.

Receiving wealth transfers from a family donor has small and not statistically significant effects on the probability of being in the labour force for males (Table 3). Regarding inheritances received from nonfamily donors, the negative impact is larger. Receiving an inheritance decreases the probability of being in the labour force by 4.24 p.p.; the estimated coefficient, however, is not statistically significant ( $\phi$-value 0.32 ). Not statistically significant estimates also emerge for the continuous-type indicators. Receiving a gift from a nonfamily donor increases the probability of being in the labour force for males. According to the binary indicator, however, the impact is small ( +1.74 p.p.) and not statistically significant ( $p$-value 0.41). Other indicators suggest similar findings.

The effect is different for females, especially in the case of nonfamily donors (Table 4). The impact of receiving an inheritance from a family donor is approximately zero, while the impact of receiving a gift from a family donor is negative and larger but not statistically significant. Receiving an inheritance from a nonfamily donor decreases the probability of being in the labour force for females by 7.86 p.p. ( $p$-value 0.023$)$. The estimated coefficients of the amount and the ratio indicators related to the receipt of an inheritance are -0.0225 ( $p$-value $0.024, \varepsilon=-0.025$ ) and -0.0544 ( $p$-value $0.033, \varepsilon=-0.026$ ), respectively. Receiving a gift from a nonfamily donor has a greater negative impact than an inheritance on the probability of being in the labour force for females. The estimated coefficient indicates a decrease of 14.36 p.p., but the estimate is not statistically significant ( $\phi$-value 0.212$)$. The estimated coefficients related to the continuous type are -0.038 and -0.1137 (both not statistically significant), respectively.

The analysis by gender confirms that the impact on the probability of being in the labour force is essentially negative. It tends to be greater in the case of gifts than in the case of 


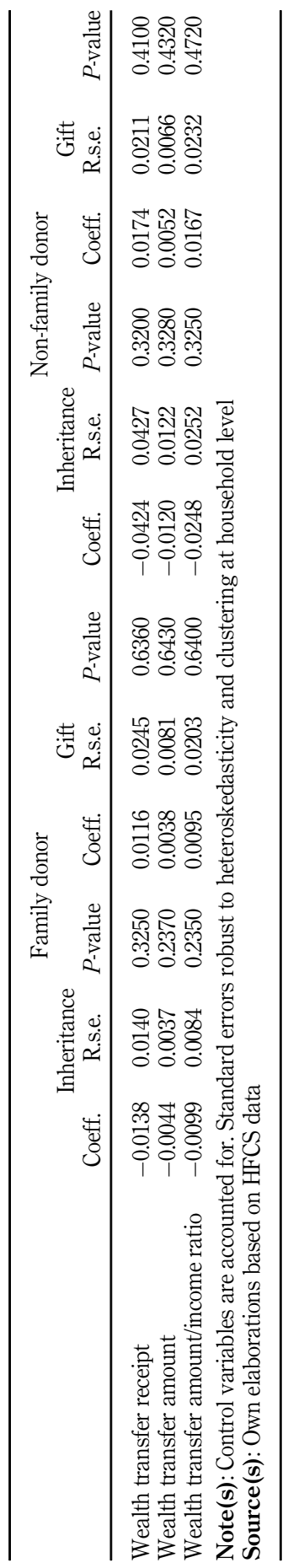

Wealth transfers and labour supply

1461

Table 3. The impact of wealth transfers on labour force participation: male 
IJM
42,8

1462

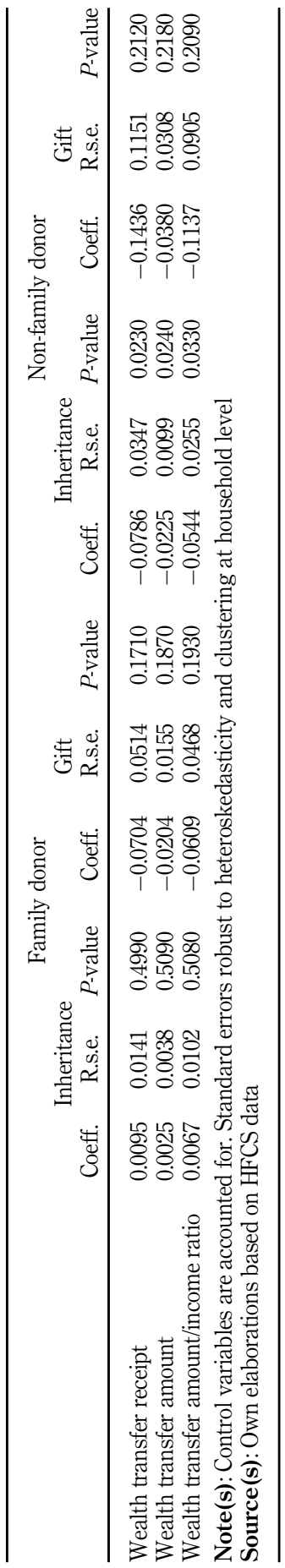

Table 4.

The impact of wealth

transfers on labour force participation: female 
inheritances, and it is proportionate to the degree of anticipation of the wealth transfer. Differences at the gender level confirm the different behaviours between males and females in the labour market. While males are strongly attached to the labour market and weakly react to the receipt of wealth transfers, the wealth effect seems to exist in the case of females by increasing the marginal utility of leisure and then reducing the labour supply.

\subsection{The case of the elderly population}

This subsection focuses on the case of elderly individuals (i.e. individuals aged 45-59) (Table 5). The interest in this subgroup is due to the possibility that receiving a wealth transfer affects retirement behaviour.

When examining only nonfamily donors, our results suggest that receiving a wealth transfer reduces the probability of being in the labour force of individuals aged 45-59. Receiving an inheritance decreases the probability of being in the labour force for individuals aged $45-59$ by 7.52 p.p., and the estimated coefficient is statistically significant ( $p$-value 0.029). Both continuous-type indicators confirm that receiving an inheritance from nonfamily donors lowers the probability of participating in the labour force. The estimated coefficient for the amount indicator is -0.0197 ( $p$-value $0.033, \varepsilon=-0.022$ ) while that for the ratio indicator is -0.044 ( $p$-value $0.04, \varepsilon=-0.021)$. Regarding gifts, we find that receiving a gift from a nonfamily donor decreases the probability of being in the labour force by 16.18 p.p. The estimated coefficient was not statistically significant ( $p$-value 0.203). Continuous-type indicators confirm the mentioned effect, with estimated coefficients equal to $-0.0423(p$-value $0.172)$ for the amount indicator and to -0.1132 ( $p$-value $0.0 .21, \varepsilon=-0.042)$ for the ratio indicator, which is statistically significant.

Therefore, the evidence for individuals aged $45-59$ is consistent with the existing evidence, as seen in Brown et al. (2010).

\subsection{The role of education}

We analysed the result by educational level by splitting the sample between low-middle and highly educated and running separated estimations (Tables 6 and 7). If the educational level proxies job quality, this analysis sheds light on further heterogeneous effects of wealth transfer on the labour supply. Consistent with the previous analysis, the estimates tend to be statistically significant in the case of inheritances from nonfamily donors; furthermore, consistent with Kaplan (1987), the impact is greater for individuals with low/middle education than for those with high education. Receiving an inheritance from nonfamily donors reduces the probability of being in the labour force by 7.66 p.p. ( $p$-value 0.07$)$ for individuals with a low/middle level of education and by 4.54 p.p. for highly educated individuals ( $p$-value equal to 0.135$)$. The literature on the inequality effects of wealth transfer (e.g. Elinder $e$ al., 2018) stresses that while richer individuals are likely to receive larger amounts, poorer individuals receive larger amounts relative to their pretransfer wealth. Because individuals with a low/ middle level of education are likely to earn less labour income than highly educated individuals, the relative magnitude of the inheritance/income ratio would be greater for the former group. This agrees with the greater negative impact on labour supply we find for individuals with a low/middle education level.

\subsection{Nonlinear effects}

We tested the possibility of nonlinear effects of wealth transfers replacing continuous indicators by dummy variables. In the case of the wealth transfer amount, the dummy variables are assigned a value of one if the amount is, respectively, greater than $50000 \mathrm{PPP}$ euros, 100000 PPP euros and 200000 PPP euros and zero otherwise. In the case of the wealth 
IJM
42,8

1464

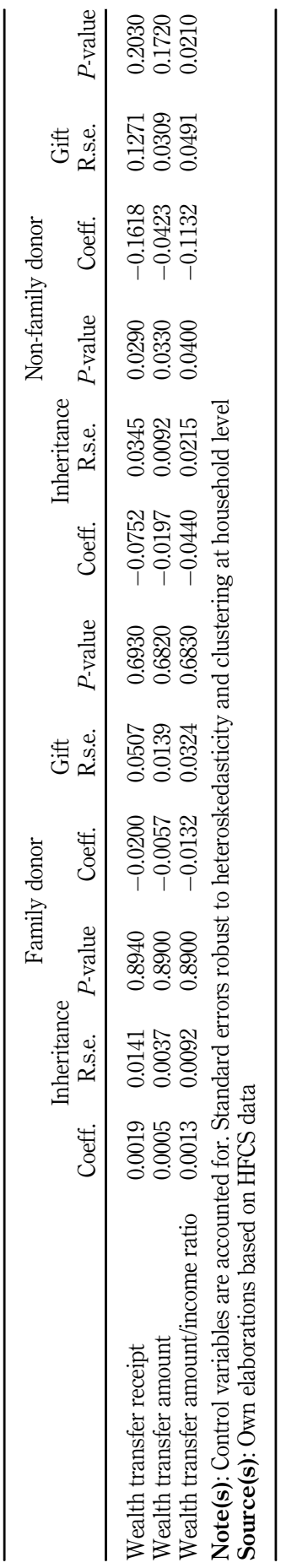

Table 5.

The impact of wealth transfers on labour force participation: elderly 


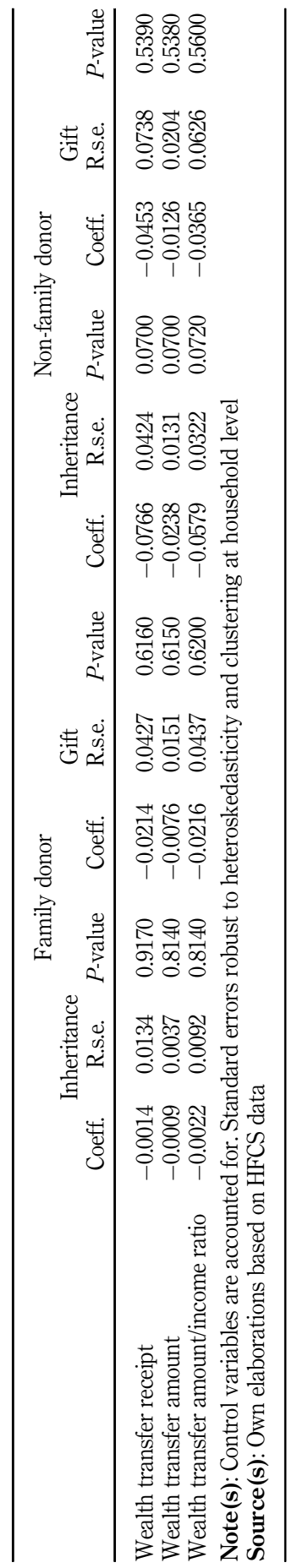

Wealth transfers and labour supply

1465

Table 6.

The impact of wealth transfers on labour force participation: low-middle educated 
IJM

42,8

1466

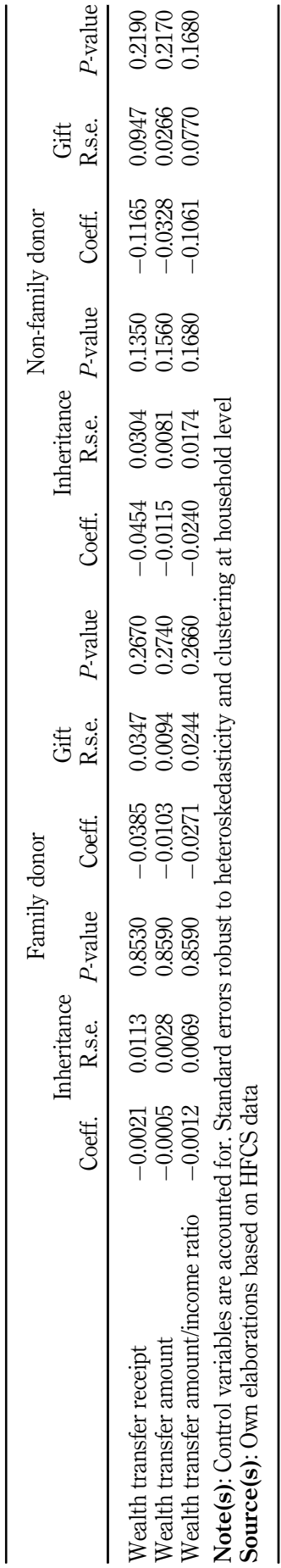

Table 7.

The impact of wealth

transfers on labour

force participation:

highly educated 
transfer amount/income ratio, the dummy variables are assigned a value of one if the ratio is, in turn, greater than 2,5 and 10 and zero otherwise. The related estimates are reported in the Appendix (Table A8) and show that the negative impact of both inheritances and gifts on labour force participation increases more than proportionally as the amount and the ratio increase, suggesting that the effect is nonlinear. Consistent with the benchmark estimates, the results are statistically significant in the case of nonfamily donors and especially for inheritances.

\subsection{The impact of wealth transfers on working hours}

We add an investigation of the impact of having received a wealth transfer on working hours to the benchmark analysis. Because working hours are only observed for employed individuals, when estimating how individuals react to the receipt of a wealth transfer, one must account for selection into work. Therefore, we preliminarily model the probability of being employed to determine the inverse Mills ratio term (IMR) by estimating a probit model and then estimate working hours equations including the selectivity term by using an IV2SLS estimator. Because this procedure determines incorrectly biased standard errors if the coefficient on IMR is not zero, we adopt bootstrapping to produce corrected standard errors.

We report the estimates for the entire sample in the Appendix (Table A9). They reveal that the impact of receiving a wealth transfer is small and not significant. The sign of the coefficients is negative in the case of family donors and positive for nonfamily donors. Subgroups estimations confirm these findings.

The nonsignificant effect along the intensive margins agrees with previous research (e.g. Holtz-Eakin et al., 1993; Sila and Sousa, 2014). A possible explanation is the regulation of working hours and then its effects on the possibility an individual adapts his/her labour supply to their preferences. In countries such as European countries that are characterized by rigidities in working hours [10], wealth shocks are more likely to affect the extensive margin than the intensive margin.

\section{Conclusions}

In this article, we have studied the impact of having received a wealth transfer on labour market participation in 14 European Union countries using data from the 2014 wave of the HFCS database. The main novelty of our research is considering two different types of wealth transfers, namely, inheritances and gifts, and providing separate estimations by gender.

When examining the differences between inheritances and gifts, we stress that the impact on labour force participation associated with the receipt of a gift is negative and greater in magnitude than the impact of an inheritance. We also find that there is important heterogeneity in these effects; they are larger for females (and very small or negligible for males) and larger for older people and workers with less than a high-level education, but the negative impact is always larger for gifts than for inheritances.

We consider this difference between gifts and inheritances to be very important because the literature on wealth transfers and employment has been almost exclusively focused on inheritances. This finding, however, must be treated with some caution. First, estimates for gifts are not statistically significant at the 10\% level. Second, the strict comparability between inheritances and gifts is somehow difficult because the identified local average treatment effect returns the causal impact among the compliers, which, in turn, are different between inheritances and gifts because the adopted instruments are different. Nevertheless, our results suggest that differences between inheritances and gifts deserve further investigation, and the ageing process of EU countries and the risk of secular stagnation should also be considered. 
IJM

42,8

1468

Regarding the ageing process in EU countries, there has been a growing interest in active ageing and even in what determines working beyond retirement (Anxo et al., 2012, 2019). However, in ageing societies, the heirs will be increasingly older; therefore, we should expect that more people would leave the labour force when receiving an inheritance. Furthermore, donors may opt to increase the size and frequency of gifts, partially or totally replacing a future bequest because of generalized ageing. Because of the larger effect estimated for gifts, this may be detrimental for the economy through a decrease in participation rates.

However, the heterogeneity of the impacts we find by gender (as the impacts are almost exclusively significant for females) may provide a richer interpretation. Because of the unequal distribution of housework and caregiving by gender, the negative impact of wealth transfers might be more a "caregiving effect" (i.e. replacing working hours at the market with working hours at home) instead of a "Carnegie effect" (i.e. replacing working hours with leisure hours). In the context of ageing societies with growing needs for long-term care for increasingly more individuals, we consider that this "caregiving effect" should be seriously considered and analysed using other datasets, including information about housework duties, caregiving time, social services, members of the family with disabilities, etc. and with a focus on the impact of wealth transfers by gender, which has been scarcely treated in the literature on inheritance and employment (Doorley and Pestel, 2020; Bø et al., 2019).

In addition, some macroeconomic changes may also increase the importance and the potential impact of inheritances and gifts on employment choices. When productivity increases for a long time, the importance of inheritances and even gifts will not be very large because the lifetime resources of the potential heirs will outpace those of parents or other potential donors (Cox, 2014). However, when economic growth is low for long periods, inheritances and gifts are potentially much more important to understand labour supply choices. Some economists prominently Summers (2015) - consider that we are at the beginning of a secular stagnation period with nominal interest rates close to the zero lower bound and very slow economic growth. In this economic context, we may expect that wealth transfers as inheritances and gifts could have more influence on the employment status of individuals. Joining the potential effects of ageing and secular stagnation, the negative impacts of wealth transfers on labour participation might be larger in the future, favouring the trend of low growth.

Wealth transfer taxation may reverse or partially compensate for these incentives to decrease labour force participation. In fact, the current social debate on wealth inequality, social mobility and inheritances is closely related to taxation (e.g. Piketty, 2014). This literature has usually considered that inheritances and gifts are equivalent, but our results suggest that they are not in terms of their impacts on labour force participation, which should be considered in the analyses of optimal taxation of wealth transfers. To the best of our knowledge, there are only empirical analyses of taxation showing that they are not perfect substitutes, at least among the richest individuals (Poterba, 2001). For similar reasons, we believe that future research should assess whether inheritances and gifts have the same impact on social mobility. Linking with the above discussion on the possibility of a "caregiving effect" instead of a "Carnegie effect" in EU ageing societies, we consider that the discussion on the effects of changes in taxation on inheritances and gifts should explicitly include the possibility of side effects on caregiving because of the unequal distribution of housework and caregiving by gender.

\section{Notes}

1. Data on individual/household incomes were also converted using purchasing power parity (PPP).

2. The literature has shown that receiving an inheritance is positively associated with staying or becoming self-employed (e.g. Holtz-Eakin et al., 1994; Hurst and Lusardi, 2004), especially in presence of liquidity constraints. 
3. The amount of wealth transfers has been scaled by the income of other household members rather the entire household income to avoid endogeneity problems between that indicator and the outcome variable.

4. We also considered the possibility that continuous indicators have nonlinear effects on the probability of being in the labour force. More detailed information is provided in Section 5.5.

5. During the 2008-2013 period, the wealth transfer taxation in Europe was oriented towards reductions (e.g. Austria, France, Ireland, and the Netherlands) or, at least, it remained stable. Conversely, the period analysed was generally characterized by a slight increase in labour taxes. For example, the tax wedge slightly increased in many European countries while Hungary and Germany were some exceptions.

6. We also run a specification where the wealth transfer amount is divided by total household income. The estimation results slightly change in magnitude, but the statistical significance and the essence of the estimations are unchanged.

7. Differently from the Cragg-Donald Wald $F$ statistic, the Kleibergen-Paap $r k$ Wald $F$ statistics is robust against violations of the i.i.d. assumption.

8. Table A5 reports the estimated coefficients of the control variables related to inheritance and gifts for family donors. The estimates for other subgroups are very similar.

9. The standard errors for gifts are often greater than those for inheritances, suggesting a greater variability in their estimated coefficients.

10. In this vein, $60 \%$ of our sampled individuals work 40 or $35 \mathrm{~h}$ per week.

\section{References}

Angrist, J.D. and Pishke, J.S. (2009), Mostly Harmless Econometrics: An Empiricist's Companion, Princeton University Press, Princeton, New Jersey.

Anxo, D., Ericson, T. and Jolivet, A. (2012), "Working longer in European countries: underestimated and unexpected effects", International Journal of Manpower, Vol. 33 No. 6, pp. 612-628.

Anxo, D., Ericson, T. and Jolivet, A. (2019), "Beyond retirement: who stays at work after the standard age of retirement?", International Journal of Manpower, Vol. 40 No. 5, pp. 917-938.

Barro, R. (1974), “Are government bonds net wealth?", Journal of Political Economy, Vol. 82, pp. 1095-1117.

Bellemare, M.F. and Wichman, C.J. (2020), "Elasticities and the inverse hyperbolic sine transformation”, Oxford Bulletin of Economics and Statistics, Vol. 82 No. 1, pp. 50-61.

Blau, F.D. and Kahn, L.M. (2007), "Changes in the labor supply behavior of married women: 19802000", Journal of Labor Economics, Vol. 25 No. 3, pp. 393-438.

Bø, E.E., Halvorsen, E. and Thorsen, T.O. (2019), "Heterogeneity of the Carnegie effect", Journal of the Human Resources, Vol. 54 No. 3, pp. 726-759.

Brown, J.R., Coile, C.C. and Weisbenner, S.J. (2010), "The effect of inheritance receipt on retirement", The Review of Economics and Statistics, Vol. 92 No. 2, pp. 425-434.

Cesarini, D., Lindqvist, E., Notowidigdo, M.J. and Ostling, R. (2017), “The effect of wealth on individual and household labor supply: evidence from Swedish lotteries", American Economic Review, Vol. 107, pp. 3917-3946.

Cox, D. (2014), "Inheritance, bequest, and labor supply", IZA World of Labor, Vol. 69, pp. 1-10.

Doorley, K. and Pestel, N. (2020), "Labour supply after inheritances and the role of expectations", Oxford Bulletin of Economics and Statistics, Vol. 82 No. 4, pp. 843-863.

Elinder, M., Erixon, O. and Ohlsson, H. (2012), "The impact of inheritances on heirs' labor and capital income", B.E. Journal of Economic Analysis and Policy, Vol. 12 No. 1, pp. 1-35. 
IJM

42,8

1470
Elinder, M., Erixson, O. and Waldenström, D. (2018), "Inheritance and wealth inequality: evidence from population registers", Journal of Public Economics, Vol. 165, pp. 17-30.

European Commission (2015), Cross-country Review of Taxes on Wealth and Transfers of Wealth. Taxation Studies 0051, Directorate General Taxation and Customs Union, Bruxelles.

Eurostat (2014), Transport Accidents Statistics, Eurostat Statistics, Luxembourg.

Holtz-Eakin, D., Joulfaian, D. and Rosen, H.S. (1993), "The Carnegie conjecture: some empirical evidence", The Quarterly Journal of Economics, Vol. 108 No. 2, pp. 413-435.

Holtz-Eakin, D., Joulfaian, D. and Rosen, H.S. (1994), "Entrepreneurial decisions and liquidity constraints", The RAND Journal of Economics, Vol. 25 No. 2, pp. 334-347.

Hurst, E. and Lusardi, A. (2004), "Liquidity constraints, household wealth, and entrepreneurship", Journal of Political Economy, Vol. 112 No. 2, pp. 319-347.

Imbens, G., Rubin, D. and Sacerdote, B. (2001), "Estimating the effect of unearned income on labor earnings, savings, and consumption: evidence from a survey of lottery players", American Economic Review, Vol. 91, pp. 778-794.

Joulfaian, D. and McGarry, K. (2005), "Estate and gift tax incentives and inter vivos giving”, National Tax Journal, Vol. 57 No. 2, pp. 429-444.

Joulfaian, D. and Wilhelm, M.O. (1994), "Inheritance and labor supply", The Journal of Human Resources, Vol. 29 No. 4, pp. 1205-1234.

Kaplan, H.R. (1987), "Lottery winners: the myth and reality", Journal of Gambling Behavior, Vol. 3 No. 3, pp. 168-178.

McGarry, K. (2013), “The estate tax and inter vivos transfers over time”, American Economic Review, Vol. 103 No. 3, pp. 478-483.

Picchio, M., Suetens, S. and van Ours, J.C. (2018), "Labour supply effects of winning a lottery", The Economic Journal, Vol. 128, pp. 1700-1729.

Piketty, T. (2014), Capital in the Twenty-First Century, Harvard University Press, Cambridge, Massachusetts.

Poterba, J.M. (2001), "Estate and gift taxes and incentives for inter vivos giving in the US", Journal of Public Economics, Vol. 79 No. 1, pp. 237-264.

Sila, U. and Sousa, R.M. (2014), "Windfall gains and labour supply: evidence from the European household panel”, IZA Journal of Labor Economics, Vol. 3 No. 1, pp. 1-27.

Stock, J. and Yogo, M. (2005), "Testing for weak instruments in linear IV regression”, in Andrews, D.W.K. (Ed.), Identification and Inference for Econometric Models, Cambridge University Press, New York.

Summers, L.H. (2015), "Demand side secular stagnation”, American Economic Review, Vol. 105 No. 5, pp. $60-65$.

Taylor, M.P. (2001), "Self-employment and windfall gains in Britain: evidence from panel data", Economica, Vol. 68, pp. 539-565.

\section{Corresponding author}

Dario Sciulli can be contacted at: d.sciulli@unich.it 


\section{Appendix}

Wealth

transfers and

labour supply

\begin{tabular}{|c|c|c|c|c|c|c|c|}
\hline \multirow[b]{2}{*}{ Centile } & \multirow[b]{2}{*}{ Inheritance } & \multirow[b]{2}{*}{ Gift } & \multicolumn{2}{|c|}{ Family donor } & \multicolumn{2}{|c|}{ Non-family donor } & \multirow{3}{*}{1471} \\
\hline & & & Inheritance & Gift & Inheritance & Gift & \\
\hline \multirow{4}{*}{$\begin{array}{l}25 \\
50 \\
75 \\
90\end{array}$} & \multirow{4}{*}{$\begin{array}{r}8.621 \\
25.641 \\
76.923 \\
179.245\end{array}$} & \multirow{4}{*}{$\begin{array}{r}9.434 \\
30.303 \\
89.286 \\
199.725\end{array}$} & \multirow{4}{*}{$\begin{array}{r}9.106 \\
27.353 \\
79.621 \\
191.667\end{array}$} & \multirow{5}{*}{$\begin{array}{r}10.256 \\
33.981 \\
92.593 \\
208.333\end{array}$} & \multirow{5}{*}{$\begin{array}{r}5.128 \\
17.241 \\
59.874 \\
139.889\end{array}$} & \multirow{5}{*}{$\begin{array}{r}3.774 \\
14.851 \\
47.170 \\
144.928\end{array}$} & \\
\hline & & & & & & & \\
\hline & & & & & & & Distribution of wealth \\
\hline & & & & & & & transfer amount (in \\
\hline \multicolumn{4}{|c|}{ Source(s): Own elaborations based on HFCS data } & & & & PPP EUR '000) \\
\hline
\end{tabular}


IJM
42,8

1472

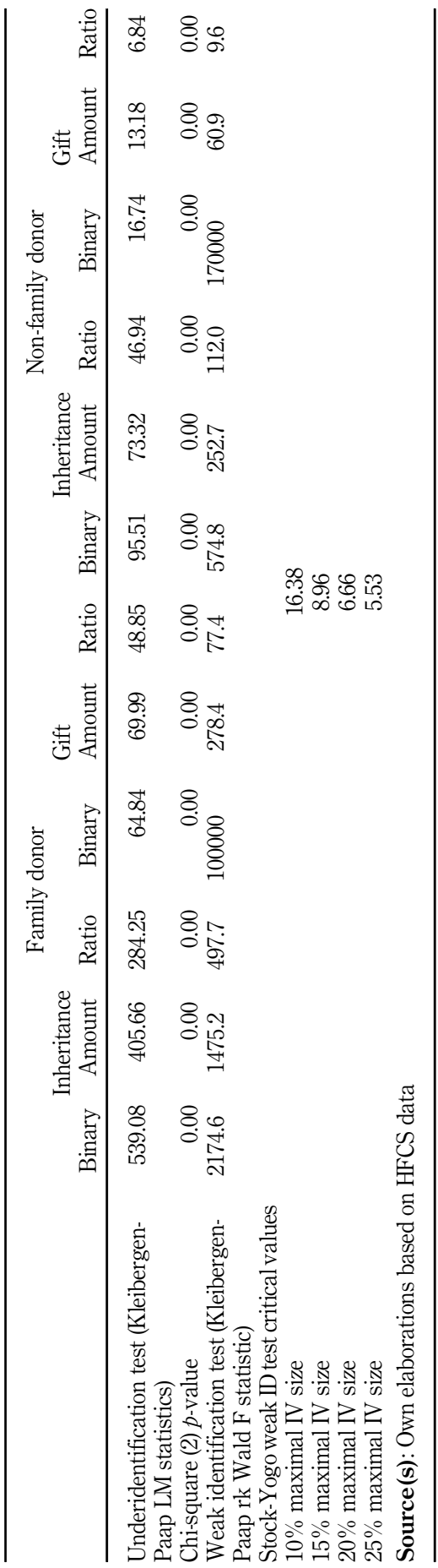

Table A2.

Under-identification

and weak identification tests: whole sample 


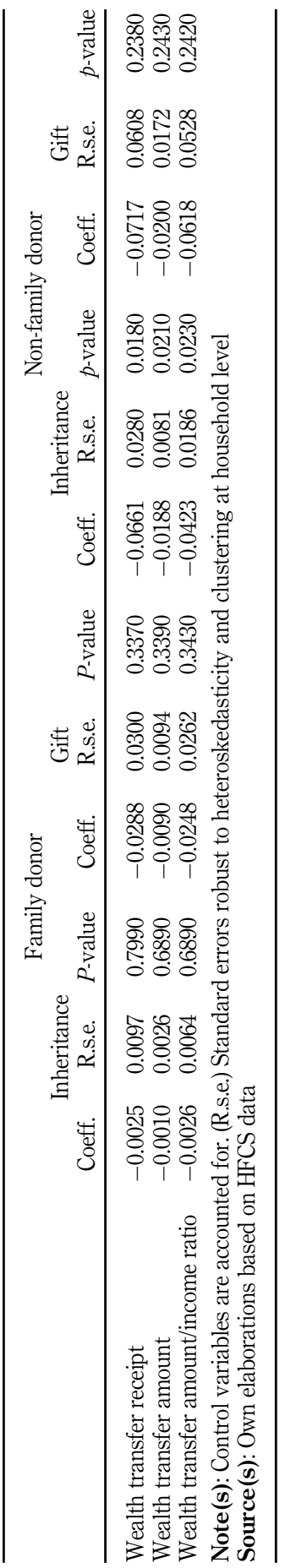

Wealth transfers and labour supply

1473

Table A3.

The impact of wealth transfers on labour force participation: whole sample, accounting for GDP growth rate indicator 
IJM
42,8

\section{4}

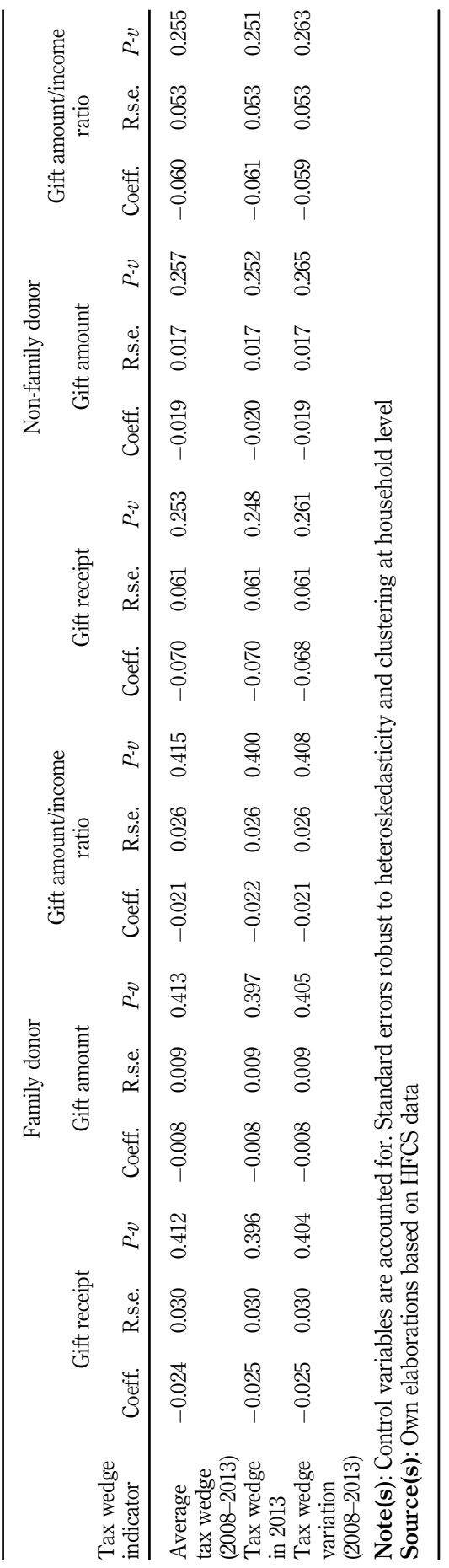

Table A4.

The impact of gift on labour force participation: whole sample, accounting for tax wedge indicators

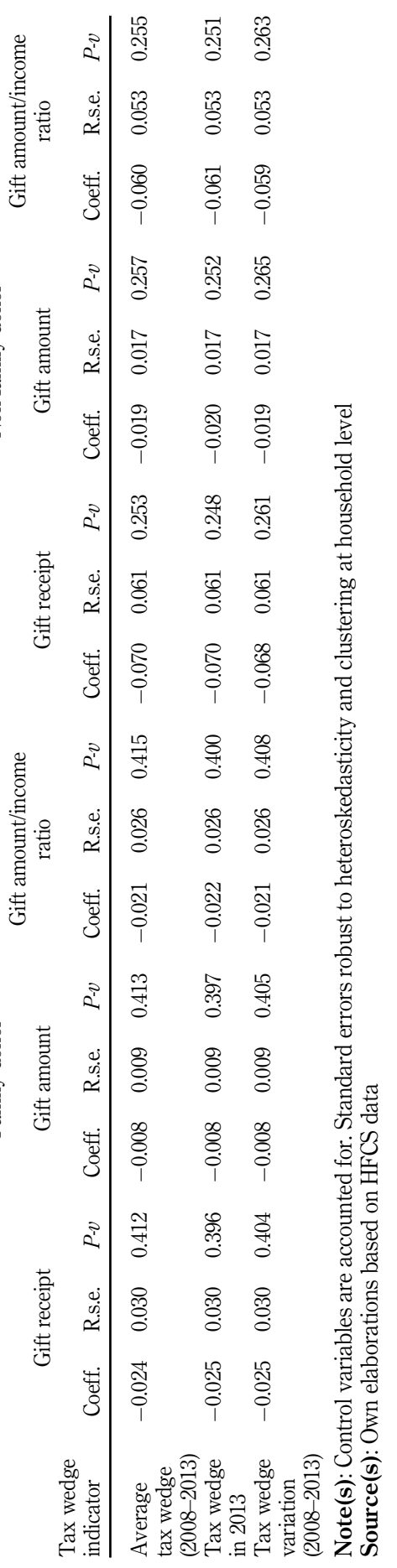




\begin{tabular}{|c|c|c|c|c|c|c|c|}
\hline & \multicolumn{3}{|c|}{ Inheritance } & \multicolumn{3}{|c|}{ Gift } & \multirow{2}{*}{$\begin{array}{l}\text { Wealth } \\
\text { transfers and }\end{array}$} \\
\hline & Coeff. & R.s.e. & $P$-value & Coeff. & R.s.e. & $P$-value & \\
\hline Female & -0.037 & 0.005 & 0.000 & -0.037 & 0.005 & 0.000 & \\
\hline Age $25-34$ & \multicolumn{6}{|c|}{ base-category } & \multirow{5}{*}{1475} \\
\hline Age 35-44 & 0.013 & 0.008 & 0.103 & 0.012 & 0.008 & 0.118 & \\
\hline Age $45-54$ & -0.029 & 0.009 & 0.001 & -0.030 & 0.009 & 0.000 & \\
\hline Age 54-59 & -0.149 & 0.013 & 0.000 & -0.150 & 0.013 & 0.000 & \\
\hline Low education & \multicolumn{6}{|c|}{ base-category } & \\
\hline Medium education & 0.013 & 0.012 & 0.255 & 0.013 & 0.012 & 0.246 & \\
\hline High education & 0.039 & 0.011 & 0.001 & 0.040 & 0.011 & 0.000 & \\
\hline Spouse at work & 0.027 & 0.006 & 0.000 & 0.028 & 0.007 & 0.000 & \\
\hline Married & -0.013 & 0.006 & 0.045 & -0.013 & 0.006 & 0.044 & \\
\hline Number of children $0-6$ & -0.021 & 0.005 & 0.000 & -0.021 & 0.005 & 0.000 & \\
\hline Born in foreign country & 0.022 & 0.010 & 0.026 & 0.021 & 0.010 & 0.032 & \\
\hline Work experience/potential work experience & 0.008 & 0.001 & 0.000 & 0.008 & 0.001 & 0.000 & \\
\hline Work experience/potential work experience square & 0.000 & 0.000 & 0.000 & 0.000 & 0.000 & 0.000 & \\
\hline Unemployment rate in 2013 & 0.029 & 0.006 & 0.000 & 0.029 & 0.006 & 0.000 & \\
\hline Austria & \multicolumn{6}{|c|}{ base-category } & \\
\hline Belgium & -0.058 & 0.018 & 0.001 & -0.057 & 0.018 & 0.001 & \\
\hline Germany & 0.008 & 0.009 & 0.371 & 0.008 & 0.009 & 0.398 & \\
\hline Estonia & -0.118 & 0.021 & 0.000 & -0.119 & 0.021 & 0.000 & \\
\hline France & -0.101 & 0.023 & 0.000 & -0.100 & 0.023 & 0.000 & \\
\hline Hungary & -0.124 & 0.025 & 0.000 & -0.125 & 0.025 & 0.000 & \\
\hline Ireland & -0.252 & 0.041 & 0.000 & -0.253 & 0.042 & 0.000 & \\
\hline Luxembourg & -0.072 & 0.013 & 0.000 & -0.073 & 0.013 & 0.000 & \\
\hline Latvia & -0.166 & 0.039 & 0.000 & -0.167 & 0.039 & 0.000 & Table A \\
\hline The Netherland & -0.050 & 0.015 & 0.001 & -0.051 & 0.016 & 0.001 & 1abie A5. \\
\hline Poland & -0.144 & 0.025 & 0.000 & -0.144 & 0.025 & 0.000 & $\begin{array}{l}\text { Labour lorce } \\
\text { participation equation }\end{array}$ \\
\hline Portugal & -0.285 & 0.060 & 0.000 & -0.286 & 0.060 & 0.000 & with binary indicators: \\
\hline Slovenjia & -0.108 & 0.028 & 0.000 & -0.109 & 0.028 & 0.000 & control variables and \\
\hline Slovak Republic & -0.216 & 0.047 & 0.000 & -0.217 & 0.048 & 0.000 & country dummy \\
\hline Constant & 0.276 & 0.048 & 0.000 & 0.277 & 0.048 & 0.000 & variables, whole \\
\hline Source(s): Own elaborations based on HFCS data & & & & & & & \\
\hline
\end{tabular}

\begin{tabular}{|c|c|c|c|c|c|c|}
\hline & & Variance & Mean & $\rho$ & $\rho_{z}$ & Moulton factor \\
\hline \multirow{3}{*}{ Family donor } & Inheritance receipt & 9531193 & 5036.275 & 0.00039 & 0.00889 & 1.012 \\
\hline & Inheritance amount & 9531193 & 5036.275 & 0.00040 & 0.00889 & 1.012 \\
\hline & Inheritance ratio & 9531193 & 5036.275 & 0.00040 & 0.00889 & 1.012 \\
\hline \multirow{3}{*}{ Non-Family donor } & Inheritance receipt & 6023425 & 4391.186 & 0.00054 & 0.00148 & 1.002 \\
\hline & Inheritance amount & 6023425 & 4391.186 & 0.00054 & 0.00148 & 1.002 \\
\hline & Inheritance ratio & 6023425 & 4391.186 & 0.00054 & 0.00148 & 1.002 \\
\hline \multirow[t]{3}{*}{ Family donor } & Gift receipt & 9531193 & 5036.275 & 0.00041 & 0.04192 & 1.058 \\
\hline & Gift amount & 9531193 & 5036.275 & 0.00042 & 0.04192 & 1.059 \\
\hline & Gift ratio & 9531193 & 5036.275 & 0.00042 & 0.04192 & 1.059 \\
\hline \multirow[t]{3}{*}{ Non-Family donor } & Gift receipt & 6023425 & 4391.186 & 0.00054 & 0.00937 & 1.014 \\
\hline & Gift amount & 6023425 & 4391.186 & 0.00054 & 0.00937 & 1.014 \\
\hline & Gift ratio & 6023425 & 4391.186 & 0.00054 & 0.00937 & 1.014 \\
\hline
\end{tabular}

Table A6.

Moulton factor: whole sample 
IJM

1476

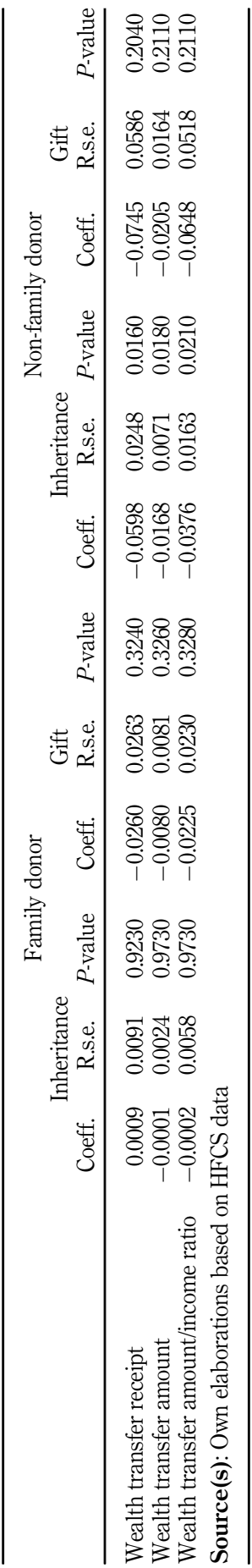

Table A7.

The impact of wealth transfers on labour force participation: whole sample, including selfemployed 
IJM
42,8

1478

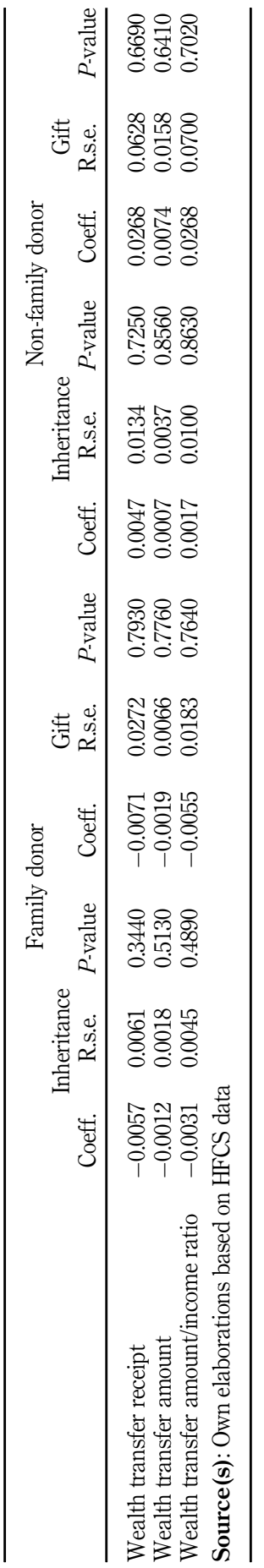

Table A9.

The impact of wealth transfers on working hours: whole sample 